\title{
Ernest Lluch, un singular hombre de las luces
}

\author{
Vicent LLOMBART
}

Haga lo que quiera el error para defender su imperio...

podrá acaso sacrificar en la sombra de la noche a algún sabio a su furor, pero el fruto de nuestras meditaciones fermentará en el silencio,

y sus efectos serán la época feliz que disipen las preocupaciones nocivas.

Francisco Cabarrús,

Discurso sobre la libertad de Comercio

concedida por S. M. a la América Meridional (1778)

\section{El fuste ilustrado de Ernest Lluch (1937-2000)}

Tras recordar el célebre lema kantiano del «Sapere aude!» y su corolario de que no era aquella una época ilustrada sino una época en ilustración, Ernest Lluch comenzaba el primer capítulo de La Catalunya vençuda del segle XVIII (1996) y de Las Españas vencidas del siglo XVIII (1999) — dos versiones diferenciadas de una de sus más notorias obras - subrayando que doscientos años después continuamos viviendo en un época en ilustración; que los avances logrados no dispensaban de la necesidad de que las luces de la razón debieran aún disipar mucha niebla llena de oscuridad. Mostraba su acuerdo con la exclamación de Kant de que a menudo resultaba bien cómodo no estar emancipado, pero al mismo tiempo matizaba que el poder y la persistencia de la anti-ilustración nos habían revelado la 
dificultad del empeño emancipatorio. Nuevos y viejos prejuicios, nuevos y viejos intereses constituían la causa de que la condición indispensable para la operatividad de las luces — la libertad — llegara a España «con angustias inacabables de un largo parto». Y concluía ese comienzo del capítulo citando otra expresión del filósofo alemán: «para la Ilustración sólo se requiere una cosa: libertad; y las más inocente entre todas las que llevan ese nombre, es decir, la libertad de hacer uso público siempre y en todo lugar de la propia razón». Libertad acerca de la que Lluch añadía una breve pero certera apostilla: «Inocente y la más difícil, nos ha enseñado la vida de la historia».

La más difícil... y en ocasiones la más trágica, nos ha enseñado con su propia vida Ernest Lluch. Las circunstancias dramáticas de su asesinato en la noche barcelonesa del 21 de noviembre de 2000 a manos de unos terroristas de ETA son de sobra conocidas, así como la enorme conmoción que generó tanto en la sociedad catalana como en los más diferentes ámbitos de la sociedad española. No insistiré en ello, como no lo haré sobre tantas otras víctimas del terror que merecen nuestro respeto y provocan similar indignación. Pero sí quisiera indicar en esta nota en memoria de Ernest Lluch que entre los detonantes de las armas de la sinrazón que nos arrebataron en la plenitud de la vida a Ernest Lluch se encuentra, sin duda, su propio talante ilustrado. Un talante, un fuste me atrevería a decir utilizando la expresión más profunda de Isaiah Berlín, progresivamente formado tras muchos años de trabajo y reflexión, origen de los más variados y sabrosos frutos, y tan consubstancial a su persona que nunca pudo - ni quisorenunciar a él.

\section{Apuntes biográficos}

Economista, historiador de la ideas, profesor universitario, diputado, ministro, rector, periodista, conversador, editor, aficionado a las letras, a las ciencias y a la música, apasionado del deporte, maestro de numerosos discípulos, Ernest Lluch amaba con intensidad y alegría la vida (incluso había vaticinado recientemente que al haber sido ministro del ramo y al disfrutar de una robusta salud le quedaban aún muchos años por delante); vida que afrontaba con carácter jovial, mirada transparente y sonrisa seductora, y con una curiosidad persistente hacia todo aquello que pudiera explicar la propia vida o mejorar las condición humana.

Nacido en Vilassar de Mar (en la cercanías de Barcelona) en el seno de una modesta familia de artesanos de marroquinería y del textil en 1937, es decir, en plena Guerra Civil. En sus años de juventud ejerció durante tres años como viajante de comercio para vender cinturones, tirantes, ligas, sedas... del taller familiar, conociendo así la dura España de la posguerra desde el tren y el autobús. En 1957 comienza sus estudios en la Facultad — «bastante aburrida» escri- 
birá después - de Económicas de la Universidad de Barcelona, de la que guarda un buen recuerdo de la docencia de Jaume Vicens y Vives, Fabián Estapé y Jordi Nadal, y en la que se licencia con premio extraordinario en 1961. Desde ese año a 1966 pertenece como profesor ayudante al Seminario de Política Económica dirigido por Fabián Estapé y acude en 1963 a París con una beca de ampliación de estudios a la École Pratique des Hautes Études de la Universidad de la Sorbona, donde trabaja con Pierre Vilar, Jean Wieller y Andre Pietre y donde trata de desarrollar su primer proyecto de tesis doctoral sobe el pensamiento económico del grupo Chez Guillaumin-Journal des Economistes y su influencia en la España de la segunda mitad del siglo XIX. Diversas dificultades le hicieron replantearse ese proyecto de tesis y centrarse un periodo anterior referido especialmente a Cataluña.

En 1966 es expulsado de la Universidad de Barcelona por solidarizarse con el Sindicato Democrático de Estudiantes. La expulsión se sustancia mediante un expediente incoado y decidido por García Valdecasas, Batlle Vázquez y Lora Tamayo. Durante los cuatro años siguiente, en los que ya estaba en plena preparación y redacción de la tesis doctoral, sus medios de vida provendrán —además de un pequeño contrato en la Cátedra de Historia de las Doctrinas Económicas de la Universidad Complutense de Madrid- de algunos trabajos que luego denominará algo injustamente «pro pane lucrando», como son sus estudios de urbanismo, de economía regional, sobre las Cajas de Ahorro y de su participación en varios Servicios de Estudios: los del Banco de Urquijo, Banca Catalana o del Área Metropolitana de Barcelona. Aún tendría tiempo durante esos años 60 de comenzar a publicar artículos relacionados con la tesis (sobre Flórez Estrada, Romá i Rosell o las instituciones ilustradas de Girona) y participar activamente en actividades divulgadoras y cívicas: numerosos artículos breves en la revista de la Abadía de Montserrat Serra D'Or, en los estudios del Círculo de Economía y en los comienzos de sus tareas como editor.

En 1970 presenta los tres amplios volúmenes de su tesis doctoral: El pensamiento económico en Cataluña entre el renacimiento económico y la revolución industrial: la irrupción de la escuela clásica y la respuesta proteccionista. Lluch quiso subrayar el inusual hecho de que los diversos miembros del Tribunal se leyeran la voluminosa tesis y le hicieran oportunas observaciones sobre los aspectos innovadores del trabajo. Así ocurrió con Pedro Schwarz, Juan Velarde, Sebastián Martín-Retortillo y Joan Sardá, presididos por Fabián Estapé.

En octubre de ese mismo año se incorpora a la Facultad de Económicas de la Universidad de Valencia gracias a las gestiones de Rafael Martínez Cortiña, lo que le permite una primera profesionalización universitaria, aunque interina, hasta 1975. En 1971-72 crea el Seminario de Historia de las Doctrinas Econó- 
micas en Valencia — el único existente en España además de la «Cátedra» correspondiente y de muy distinta orientación que dirige Pedro Schwarz en Madridcon la participación permanente de Salvador Almenar, Segundo Bru, Santiago Lanzuela (durante dos años) y el que suscribe. Seminario que superando obstáculos burocráticos y discriminaciones políticas despliega una intensa y variada actividad: celebración de sesiones académicas abiertas a muchos otros profesores de la Facultad y de fuera de la Facultad, de cursos de doctorado sobre recientes aportaciones y controversias teóricas en economía generalmente heterodoxa, impulso de tesis, tesinas y trabajos de curso, realización de traducciones, de investigaciones conjuntas, de primeras publicaciones, asistencia a Congresos, restablecimiento de instituciones económico-políticas de la maltrecha sociedad civil valenciana, por no hablar de la abundante y explícita actividad política antifranquista.

Todo ello no es óbice para el trabajo investigador más silencioso e individual. En 1973 publica una versión reducida y muy revisada de su tesis con un nuevo título: El pensament econòmic a Catalunya (1760-1840), con un subtítulo de cierto sabor marxista que con el tiempo el propio Lluch consideraría poco afortunado, Els orígens ideològics del proteccionisme i la presa de consciència de la burgesia catalana. El esfuerzo de revisión de la tesis original fue importante y ahora estamos ante un libro en principio a caballo entre el siglo XVIII y XIX y en el que se replantean, consciente o inconscientemente, muchas de las hipótesis iniciales. El libro recibió el premio catalán de investigación y ha sido fuente constante a lo largo de su vida de numerosos trabajos, en especial sobre las cuestiones ya planteadas pero sólo incipientemente desarrolladas del siglo XVIII. Incluso puede afirmarse que en lugar de avanzar hacia el siglo XIX como era su intención primigenia, Lluch en sus trabajos de madurez fue retrocediendo a lo largo del setecientos hasta la Guerra de Sucesión, hacia los problemas ideológicos que generó la Guerra en Cataluña y en el resto de la Corona de Aragón. En cualquier caso, El pensament econòmic a Catalunya es una obra de referencia fundamental en la trayectoria intelectual de Ernest Lluch.

En 1975 superó con unánime éxito la oposición a la Agregaduría valenciana de Historia de las Doctrinas Económicas. Con tal motivo redactó una extensa Memoria que ha sido fuente de diversas publicaciones posteriores sobre algunos de los temas por los que ha adquirido mayor celebridad entre la profesión: la relevancia del enfoque nacional en la historia del pensamiento económico, la necesidad de aplicar métodos adecuados en el imprescindible estudio del flujo internacional de las ideas económicas y la conveniencia de aplicar también métodos cuantitativos en la historia del pensamiento económico como ocurre en la historia de la ciencia en general. Tras superar la oposición, recopiló materiales y 
redactó el libro La vía valenciana que presentó a los valencianos premios Octubre de 1975 obteniendo el galardón Joan Fuster de ensayo. Respetuosamente crítico con Fuster, Lluch planteaba en ese importante libro (pero poco conocido fuera de Valencia y que por fin acaba de publicarse de nuevo en la Editorial Afers con prólogo y epílogo de Vicent Soler) una innovadora historia económica e ideológica del País Valenciano que había seguido su propia vía hacia la industrialización, en base a pequeñas empresas dispersas, y hacia la modernidad, en base a una burguesía decimonónica homologable.

En mayo de 1975 fue detenido en Alacuás, una población cercana a Valencia, acusado de separatista por propugnar un estatuto de autonomía y propiciar una Generalitat valenciana provisional. La investigación económica e histórica y la acción política iban siempre de la mano e incluso se reforzaban mutuamente. Dos años después pasaría a ocupar un escaño de diputado en las Cortes Generales por el Partido de los Socialistas de Cataluña (PSOE) en el que permanecería durante más de diez años. Pero la cumbre de su carrera política, que para él siempre fue pasajera, fue el nombramiento en 1982 de ministro de Sanidad y Consumo en el primer gobierno socialista de Felipe González, cargo que ocupó hasta 1986. Sólo dos hechos destacaré de su etapa como ministro. El primero, consiste en su confesión de que uno de los días más felices de su vida y en el que había dormido más tranquilo fue cuando consiguió aprobar a través de la ley correspondiente la universalización de las prestaciones sanitarias a todos los ciudadanos españoles. El segundo, fue su empeño en que las nuevas responsabilidades no le impidieran seguir publicando, aprovechando las recopilaciones de materiales ya realizadas o incluso comenzando nuevas investigaciones para ello. Es de resaltar la anécdota de que tras las largas jornadas ministeriales de trabajo — solía comenzar a las 8 en punto de la mañana por lo que llegó a recibir el apodo del «abominable hombre de las $8 »-$ se desplazaba en el atardecer a la cercana Biblioteca Nacional para durante 2 ó 3 horas perfilar sus trabajos o conseguir nueva documentación. Así redactó su célebre y original libro Acaecimientos de Manuel Belgrano, fisiócrata. Como puede comprobarse en el catálogo y el cuadro sintético que expongo en páginas posteriores el empeño lo cubrió Lluch con creces respecto al siglo XVIII pues no sólo mantuvo el ritmo de publicaciones durante el periodo ministerial sino que incluso lo aumentó.

Tras conseguir la cátedra de Historia del Pensamiento Económico de la Universidad de Barcelona y dejar el ministerio en 1986 fue nombrado rector de la Universidad Internacional Menéndez Pelayo en 1988, donde impulsó la apertura y el pluralismo intelectual y científico, estableció criterios de austeridad en el gasto y de rigor académico, alimentó bien su insaciable curiosidad por las ciencias, las letras y las artes, e incluso emprendió y —lo que es más sorpren- 
dente- concluyó las importantes obras de rehabilitación del bello Palacio de la Magdalena. Durante esos años continuó publicando e investigando, e incluso encontró tiempo para realizar una estancia en el Instituto de Estudios Avanzados de Princeton donde trabajó con Albert Hirschman y John Elliot. Con el economista de origen alemán, a quien admiraba por sus ideas desde su juventud, trabó una intensa amistad que le impactó sobremanera y de tal forma que muchas de sus planteamientos paradójicos y antagónicos, o el desorden creador de la aventura humana, presentes en sus escritos de los últimos años tendrán una fuerte ascendencia hirschmaniana, no siempre bien comprendida por los historiadores. En 1992 se concedió el doctorado honoris causa de la UIMP a Hirschman, y aprovechando su estancia en Santander se celebró un fructífero Encuentro titulado «El reformismo o la pasión por lo posible», título que define bien el talante de Hirschman como define el del propio Lluch.

En 1995 se reincorpora a su cátedra de Historia del Pensamiento Económico de la Universidad de Barcelona, enseña con su habitual maestría, forma un grupo de jóvenes investigadores y duplica el número de publicaciones ya elevado durante los años anteriores. También se va introduciendo cada vez más en el principal problema de la sociedad española: la cuestión vasca. Atraído por San Sebastián y sus gentes, llega a adquirir un apartamento en los aledaños del barrio antiguo de la ciudad (sin vistas al mar pero con un espejo que él colocó en la ventana para ver el reflejo marino) y participa activamente en la búsqueda de soluciones. La metodología era la de siempre: estudiar las raíces históricas del problema, conocer personalmente a la mayor parte posible de los protagonistas, distinguir con claridad los que estaban a un lado y a otro de la democracia, la libertad y la vida, tratar de conseguir un acuerdo firme entre todas las fuerzas democráticas sin excluir en absoluto al partido nacionalista vasco, y abrir nuevas vías hacia lo posible y deseable que él pensaba, de acuerdo también con Miguel Herrero de Miñón, se podían hallar en una lectura más generosa de la Constitución.

$\mathrm{Al}$ parecer, de poco sirvió de forma inmediata la postura razonable y dialogante de Ernest. Mil razones nada pueden frente a una sola pistola. Pero el tiempo lo dirá. De momento el mensaje de Lluch y la propia persona del mensajero se han convertido en una referencia ineludible, más allá del acuerdo o el desacuerdo, cuando se aborda el problema vasco. Sin embargo, la persona de Ernest Lluch no sólo hay que comprenderla y valorarla respecto al problema vasco, sino que se debe tener un cuenta el conjunto de su obra, de sus aportaciones intelectuales, científicas y cívicas, e incluso de su contagiosa alegría por la vida. Algunos rasgos hemos ya proporcionado en estos breves apuntes biográficos. Ahora insistiremos en que su obra científica es amplia y diversa, como también su obra divulgadora en los medios de comunicación. Con mayor concreción podemos decir 
que Ernest Lluch fue un gran especialista en el siglo XVIII, uno de los principales especialistas españoles; y que a fuerza de estudiar el mil setecientos se impregnó del espíritu y los valores del siglo. Y esto es lo que concede unidad a una obra tan diversa, imposible ahora de detallar. Nos centraremos en sus trabajos sobre el siglo XVIII que suponen más de un tercio de su producción científica total (un 38 por ciento según el Curriculum vitae que presentó a la Generalitat catalana poco antes de su asesinato). Pero el método de exposición que seguiremos no es el de proponer un análisis pormenorizado de tales escritos, lo que superaría el alcance de esta nota, sino que responde u unas cuestiones previas y que pueden ser de utilidad al lector y al resto de historiadores. Así trataremos de responder a las preguntas del tipo siguiente: ¿Cuáles son los trabajos publicados por Ernest Lluch sobre el siglo XVIII? ¿Cuándo los publicó y qué versiones diferentes existen de los mismos? ¿Puede trazarse una trayectoria temporal y temática de los estudios? ¿Podemos reproducir algún escrito inédito y desconocido? ¿Es posible que Lluch llegara a formular en una breves líneas una especie de «socialismo» de raíces ilustradas, rompiendo así el vínculo que suele establecerse entre ilustración y liberalismo?

\section{Estudios sobre el siglo XVIII de Ernest Lluch}

\section{Nota bibliográfica}

El siguiente catálogo de los estudios de Ernest Lluch sobre el siglo XVIII ha partido del documento «La Bibliografía de l'Ernest Lluch» preparado por Eugeni Giral para el archivo de la futura Fundación Ernest Lluch. Ese documento que contenía 442 referencias bibliográficas, ha sido después revisado y corregido por Montserrat Lamarca llegando a las 445 referencias. Esa relación no recoge los más de un millar de artículos de periódico que Lluch publicó a lo largo de su vida. En base a esas fuentes y al curriculum vitae normalizado de 19 de septiembre de 2000 en el que Lluch presentaba 221 publicaciones para solicitar un proyecto de investigación a la Generalitat catalana, así como a informaciones adicionales, que en algunos casos ha supuesto una detenida búsqueda y una minuciosa confrontación de textos, he confeccionado el presente Catálogo.

En el Catálogo he mantenido el criterio de excluir los numerosos artículos de periódico sobre temas del siglo XVIII y he tratado de agrupar al máximo las diferentes versiones de un mismo trabajo. No es pues un Catálogo de referencias bibliográficas ni de simples escritos, sino un Catálogo de trabajos o estudios distintos en el que se trata de reducir al mínimo el número de referencias, pues lo que puede considerarse como versiones ligeramente diferentes de un 
mismo trabajo las he intentado integrar en una sola ficha bibliográfica. También conviene subrayar que el término estudio o trabajo se refiere a los publicados en medios diferentes a los periódicos o enciclopedias y que tratan de representar la obra académica o científica de Lluch en relación con el siglo XVIII. No están incluidos tampoco trabajos no publicados como son las direcciones de tesis doctorales, cursos, seminarios, conferencias, etc. Por último, una gran dificultad ha sido determinar lo que es del siglo XVIII y lo que se refiere a otras épocas. Muchos trabajos de Ernest Lluch sobre el siglo XIX e incluso sobre el Xx contienen apartados específicos sobre el siglo XVIII pues él pensaba que había una clara continuidad en las ideas y proyectos. Pero a la espera de la publicación de la bibliografía completa de Ernest Lluch he optado por la solución pragmática y sencilla de incluir sólo lo que he considerado específico del siglo XVIII.

En muchas ocasiones he tenido (y sigo teniendo) dudas sobre las opciones que he adoptado. Pero se trata de una primera aproximación, que trata de proporcionar al lector una visión de conjunto lo más completa y manejable posible, y que naturalmente deberá ser precisada y corregida en futuros estudios que aborden la amplia bibliografía y la intensa biografía de Ernest Lluch.

\section{Cátalogo de estudios sobre el siglo XVIII ${ }^{1}$}

— «Romà i Rossell, un predecessor de Malthus», Serra d'Or, VII, 4 (1965), págs. 25-26.

— «Les institucions de la Il-lustració a Girona», Anales del Instituto de Estudios Gerundenses, XVIII (1966-1967), págs. 373-376.

- El pensamiento económico en Cataluña entre el renacimiento económico y la revolución industrial: la irrupción de la escuela clásica y la respuesta proteccionista [Tesis doctoral dirigida por Fabián Estapé], Barcelona, Universidad de Barcelona-Facultad de Ciencias Económicas y Comerciales, 1970, 3 vols.

— «La Catalunya del segle XvIII i la lluita contra l'absolutisme centralista. El Proyecto del Abogado General Público de Francesc Romà i Rossell», Recerques, 1 (1970), págs. 33-50.

— «El «Diario de Barcelona», órgano de difusión y debates económicos (17921810)», Banca Catalana, 18 (1970), págs. 21-33.

— «El mercantilismo industrialista (Capmany y Caresmar) entre el capitalismo comercial y los gremios catalanes», Anales de Economía, 10 (1971), págs. 19-60.

${ }^{1}$ Para la confección de este Catálogo agradezco las observaciones y ayudas de Montserrat Lamarca, Rosa Lluch, Salvador Almenar, Lluís Argemí y Jesús Astigarraga. Como ya he indicado, el trabajo bibliográfico inicial de Emili Giral ha sido de gran ayuda. 
— «Dou: Adam Smith desde el mercantilismo», Banca Catalana, 20 (1971), págs. 27-40 [versión catalana ampliada en El pensament econòmic a Catalunya, Barcelona, 1973, págs. 189-210].

— «La Sociedad Económica de Amigos del País de Tárrega», Ilerda, XXXI (1971), págs. 143-155.

— «El caso de la no fundación de la «Sociedad Económica de Amigos del País» de Barcelona», Revista de Occidente, 115 (1972), págs. 51-70 [versión catalana en El pensament econòmic a Catalunya, Barcelona, 1973, págs. 119-134].

- «Las Sociedades Económicas de Cataluña», en Las Reales Sociedades Económicas de Amigos del País y su obra, San Sebastián, CSIC-Patronato «José Maria Quadrado de Estudios Locales», 1972, págs. 267-30770 [versión catalana en El pensament econòmic a Catalunya, Barcelona, 1973, págs. 135-166].

— «La «llustración» valenciana en el siglo XVIII. La creación de la Sociedad Económica de Amigos del País», Anales de Economía, 15 (1972), págs. 53-88.

- El pensament econòmic a Catalunya (1760-1840). Els orígens ideològics del proteccionisme i la presa de consciència de la burgesia catalana, Barcelona, Edicions 62, 1973.

— «Pensamiento económico e industrialización sedera valenciana (1740-1840)», en Siete temas sobre historia contemporánea del País Valenciano, Valencia, Universidad de Valencia-Facultad de Filosofia y Letras, 1974, págs. 57-94 [Nueva versión en La via valenciana, Valencia, Eliseu Climent, 1976; 2ª edición: Sueca, Editorial Afers, 2001, págs. 95-123].

- «La Cataluña industrial: del mercantilismo al prohibicionismo», Información Comercial Española, 517 (1976), págs. 27-36.

- «La pràctica econòmica de la Il-lustració: el valencià Manuel Sisternes i Feliu, i els seus dictàmens com a Fiscal de l'Audiència de Catalunya (1766-1779)», Primer Congreso de Historia del País Valenciano [abril de 1971], Valencia, Universidad de Valencia, 1976, vol. III, págs. 695-706.

— «Estudio preliminar», en Gregorio MaYans y SISCAR, Epistolario V, Escritos económicos [Selección, transcripción y notas de Antonio Mestre], Oliva, Ayuntamiento de Oliva, 1976, págs.VII-XXIII.

- «Jaume Caresmar i el «Discurso sobre la agricultura, comercio e industria del Principado de Cataluña» (1780)», Recerques, 10 (1980), págs. 177-181.

— «La Idea general de la policía de Tomàs Valeriola», Recerques, 10 (1980), págs. 125-137.

— «La revolució industrial a la Garrotxa (1777-1820)», Annals de l'Institut d'Estudis Gironins, XXV-II (1981), págs. 193-230 [Versión original en Amics de Besalú: IV Assemblea d'Estudis del seu Comtat. Actes i comunicacions. Camprodon 1980, (s. 1.), Amics de Besalú, 1983, págs. 279-307]. 
— «El cens del Comte de Floridablanca de 1787 (part de la Vall d'Aran)», Recerques, 11 (1981), págs. 161-177.

- «Masdevall, gran metge figuerenc de la Il.lustració», Hora Nova, 20, 9-14 de septiembre (1981), [Reproducido en Rafael PAScuET (ed.), EntreLluchs. Una aproximació empordanesa a Ernest Lluch, Figueres, Brau edicions, 2001, págs. 149-153].

—, (con Lluís Argemí) «La fisiocràcia a Espanya», Recerques, 12 (1982), págs. 7-37 [Primera versión castellana ampliada: «La fisiocracia en España», Sistema, 56 (1983), págs. 63-100; segunda versión ampliada en Agronomía y fisiocracia (1985), págs. 45-100].

— «La fisiocràcia al País Valencià: història d’un retard», L'Espill, 13-14 (1982), págs. 95-117 [Versión original en Mayans y la Ilustración. Simposio internacional en el bicentenario de la muerte de Gregorio Mayans (septiembre-octubre 1981), Oliva, Publicaciones del Ayuntamiento de Oliva, 1992, vol. II, págs. 673-696].

— «La protoindustrialització a la Garrotxa (1777-1820)», Gra de Fajol, 4 (1982), págs. 44-46.

-, (con S. Almenar) «El 'Grupo de Valencia' ante la Revolución de los precios» [título correcto: «El pensamiento económico en el País Valenciano, siglos XVI-XX»], en Història de l'economía valenciana, Llibre-catàleg amb motiu de la inaguració de la Caixa d'Estalvis Provincial de València, dia 12 d'abril de 1983 [Prólogo de Joan Lerma], València, Generalitat Valenciana - Diputació Provincial de València, 1983, págs 189-198 [versión valenciana] y págs. 301-306 [versión castellana].

- Acaecimientos de Manuel Belgrano, fisiócrata, y su traducción de las «Máximas generales del Gobierno económico de un Reyno agricultor» de François Quesnay, Madrid, Cultura Hispánica-Instituto de Cooperación Iberoamericana, 1984.

- «Cartas sobre Valentín de Foronda», Prólogo a José Manuel Barrenechea, Valentín de Foronda, reformador y economista ilustrado, Vitoria, Diputación Foral de Álava, 1984, págs. XIII-XXIV.

-, (con Lluís Argemí [y José Manuel Barrenechea]) Agronomía y fisiocracia en España (1750-1830) [Prólogo y epílogo de Fabián Estapé], Valencia, Institución «Alfonso el Magnánimo»- Institució Valenciana d’Estudis i Investigació, 1985.

- «Manuel Belgrano introduttore della fisiocrazia nell'area di lingua spagnola», Il Pensiero Economico Moderno, IV, 3 (1985), págs. 11-25 [Versión original: «Manuel Belgrano, introductor de la fisiocracia en el área de la lengua castellana», en Homenaje a José Antonio Maravall [1984-85], Madrid, Centro de 
Investigaciones Sociológicas, 1986, V, II, págs. 443-455; otra versión en Agronomía y fisiocracia, págs. 101-120].

-, (con Marianne SANDELS) «Una traducción castellana de un fisiócrata sueco», Trienio, 6 (1985), págs. 209-213.

-, (con José Manuel Barrenechea y Jesús Astigarraga) «Valentín de Foronda en Navarra y el proyecto de la traslación de aduanas de Berriechea y Zarigaiz (1781)», en I Congreso de Historia de Navarra en los siglos XVIII-XIX-XX [diciembre de 1985], Pamplona, Príncipe de Viana, 1986, Anejo IV, págs. 203-216.

-, (con José Manuel Barrenechea y Jesús Astigarraga), «En torno a una familia pamplonesa del XVIII: los Vidarte», en I Congreso de Historia de Navarra en los siglos XVIII-XIX-XX [diciembre de 1985], Pamplona, Príncipe de Viana, 1986, Anejo IV, págs. 217-229.

— «La Il-lustració a Catalunya: l'esforç per a projectar un país», L'Avenç, 103 (1987), págs. 6-17 [Versión castellana: «La Ilustración en Cataluña: el esfuerzo para proyectar un país», Sistema, 84 (1988), págs. 3-22].

- «Reflexiones sobre la Ilustración económica valenciana», en Armando Alberola y Emilio La Parra (eds.), La Ilustración española. Actas del Coloquio Internacional celebrado en Alicante [octubre de 1985], Alicante, Instituto Juan Gil Albert-Diputación Províncial de Alicante, 1987, págs. 449-452.

- «Pròleg» a Bernard de MANDEvilLE, La faula de les abelles i altres assaigs [Londres, 1714], Barcelona, Edicions 62, 1988, págs. 5-17.

— «Romà i Rossell, un pensament germànic per a Catalunya i Espanya», Estudio preliminar a Francesc Romà I Rossell, Las señales de la felicidad de España y medios de hacerlas eficaces [Madrid, 1768], Barcelona, Alta Fulla, 1989, págs. V-LIII [Otra versión en La Catalunya vençuda, págs. 179-206].

— «Condorcet et la diffusion de la «Richesse des Nations» en Espagne», en Pierre Agel et Christian Gilain (eds.), Condorcet: mathématicien, économiste, philosophe, homme politique, Paris, Minerve, 1989, págs. 188-194.

-, (con Lluís Argemí) «La difusión en España de los trabajos económicos de Condorcet y Lavoiser. Dos científicos entre el enciclopedismo y la revolución», Hacienda Pública Española, 108-109 (1989), págs. 147-156.

— «lustración y economía», Revista de Economía, 2 (1989), págs. 117-121.

- «Carles III, Madrid i la Il-lustració», L’Avenç, 131 (1989), págs. 52-55.

- «El cameralismo ante la España de Carlos III: influencia y contraste», Hacienda Pública Española, Monografía 2 (1990), págs. 73-86.

— «La Il-lustració a Catalunya: projectar el país i revisar el 1714», en Catalunya a l'època de Carles III, Barcelona, Generalitat de Catalunya, 1991, págs. 47-73. 
- «La Universitat de Cervera i els Ensenyaments Superiors a Catalunya (17141851)», en Josep Termes, Santiago Alcolea, Jordi Casassas i Ernest Lluch, La Universitat de Barcelona, Barcelona, Universitat de Barcelona, 1991, págs. 47-80 [Versión castellana, francesa e inglesa en los respectivos Suplementos, Barcelona, Universitat de Barcelona, 1991, págs. 15-19].

-, (con Salvador Almenar) «Difusión e influencia de los economistas clásicos en España (1776-1868)», en Actas do Encontro Ibérico sobre História do pensamento económico, Lisboa, CISEP, 1992, págs. 91-155 [Nueva versión: Enrique Fuentes Quintana (dir.), Economía y Economistas Españoles, Vol. IV, La economía clásica, Barcelona, Galaxia Gutenberg-Círculo de Lectores, 2000, págs. 93-170].

- «La difusión del cameralismo y de la fisiocracia a través de Europa y en especial en España, durante el siglo XVIII», en José Luis García Delgado (ed.), Economía española, cultura y sociedad. Homenaje a Juan Velarde Fuertes ofrecido por la Universidad Complutense, Madrid, Eudema, 1992, págs. 461468 [Nueva versión: Francisco Javier GuilLamón y José Javier Ruız (eds.): «Sapere aude: el «Atrévete a pensar» en el siglo de las luces», Cuadernos del Seminario Floridablanca, 3 (1996), págs. 17-26].

— «Cameralisme, Corona d'Aragó i «partit aragonès» o «militar»», Recerques, 26 (1992), págs. 35-166.

- «Prólogo» a Vicent Llombart, Campomanes, economista y político de Carlos III, Madrid, Alianza Editorial, 1992, págs. 13-21.

-, (con Lluís Argemí) «Genealogía teórica e influencia práctica del «Discurso sobre el fomento de la industria popular» (1774)», Revista de Historia Industrial, 3 (1993), págs. 179-189 [Versión original: Estudios dieciochistas en homenaje al profesor José Miguel Caso González (noviembre de 1992), Oviedo, Instituto Feijoo de Estudios del Siglo XVIII, 1995, vol. II, págs. 39-50].

- «Qüestions preliminars sobre l'Anoia, Igualada i Copons», Prólogo a Josep M. TorRAS, La comarca de l'Anoia a finals del S. XVIII: els «Qüestionaris» de Francisco de Zamora i altres descripcions (1770-1797), Barcelona, Consell Comarcal de l'Anoia-Ajuntament d'Igualada-Publicacions de l'Abadia de Montserrat, 1993, págs. 5-21.

-, (con Lluís Argemí) «Physiocracy in Spain», History of Political Economy, 26, 4 (1994), págs. 613-627.

- «La España vencida del siglo XviII. Cameralismo, Corona de Aragón, y «Partido Aragonés» o «Militar»», Sistema, 124 (1995), págs. 13-41 [Versión catalana en la Catalunya vençuda, págs. 137-178; otra vesión castellana en Las España vencidas, 1999, págs. 129-162]. 
- , (con Lluís Argemí) «La physiocracie en Espagne: une synthèse provisoire», Économies et Sociétés, 22-23 (1995), págs. 267-285 [Reproducido en Ph. Steiner, T. Delmas et B. Delmas (eds.), La diffusion internationale de la physiocratie (XVIIIe-XIXe), Grenoble, Presses Universitaires, 1995, págs. 251266].

—, (con Lluís Argemí y José Luís CARdoso) «Postface. La diffusion internationale de la physiocracie: quelques problèmes ouverts», Économies et Sociétés, 22-23 (1995), págs. 473-480 [Reproducido en Ph. Steiner, T. Delmas et B. Delmas (eds.), La diffusion internationale de la physiocratie (XVIIIe-XIXe), Grenoble, Presses Universitaires, 1995, págs. 268-280].

— «Producció de llibres en català (1476-1860), la història de la «morta viva»», L’Avenç, 189 (1995), págs. 22-27.

-, (con Eloy Fernández y Alfonso SÁnCHez) «Presentación» a Eugenio Larruga I BONETA, Memorias políticas y económicas sobre los frutos, comercio, fábricas y minas de España [Madrid, 1787-1800], Zaragoza, Gobierno de Aragón, 1995, págs. 5-9 [Estudio preliminar de Josep Fontana].

- La Catalunya vençuda del segle XVIII. Foscors i clarors de la Il.lustració, Barcelona, Edicions 62, 1996.

-, (con Alfonso SÁnchez) «Estudio introductorio» a Miguel Donoso GeneRÉS, Reflexiones politicas y económicas sobre la población, agricultura, artes, fábricas y comercio del Reyno de Aragón [Madrid, 1790], Zaragoza, Instituto Aragonés de Fomento, 1996, págs. 11-85.

— «El cameralismo más allá del mundo germánico», Revista de Economía Aplicada, IV, 10 (1996), págs. 47-54.

— «L'austriacisme persistent: 1734-1736», Initium, 1 (1996), págs. 397-404.

— «La producció de llibres en català per territoris (1476-1860)», L'Avenç, 199 (1996), págs. 20-23.

- «Un cop d'ull a la Il-lustració catalana», prefacio a Pere Gabriel (dir.), Història de la Cultura Catalana. Vol. III: El set-cents, Barcelona, Edicions 62, 1996, págs. 15-38.

— «Estudi introductori» a Junta de Comercio de Barcelona, Discurso sobre la agricultura, comercio e industria del Principado de Cataluña [Barcelona, 1780], Barcelona, Alta Fulla-Diputació de Barcelona, 1997.

- «Cameralism beyond the germanic world: a note on Tribe», History of Economic Ideas, V, 2 (1997), págs. 85-99.

- «La visión económica de Sarmiento», en O padre Sarmiento e o seu tempo. Actas do Congreso Internacional do Tricentenario do Fr. Martín Sarmiento 1695-1995 [mayo-junio de 1995], Santiago de Compostela, Conselho de Cultura Galega-Universidade de Santiago, 1997, págs. 92-102. 
- «Alarme aux endormis (1734): la difusió diplomàtica de l'austriacisme persistent», Revista Jurídica de Catalunya, XCLVI, 2 (1997), págs. 299-304.

— «Antoni de Capmany, el primer de tots», L’Avenç, 220 (1997), págs. 24-27.

— «Troballes sobre Ferran Sors», Catalunya Música, XIV, 153-154 (1997), págs. 5-9.

— «Pròleg» a Assumta Muset, Catalunya i el mercat espanyol al segle XVIII. Els traginers $i$ els negociants de Calaf $i$ Copons, Barcelona, Ajuntament d'Igualada-Publicacions de l’Abadia de Montserrat, 1997, págs. 7-13.

- «Pròleg» a Josep M. GAY, El Corregidor a Catalunya, Madrid, Marcial PonsSeminario de Historia del Derecho de Barcelona, 1997, págs. 17-20.

- «Jansenismo y polizeiwissenschaft en Adam Smith», Revista de economía aplicada, VI, 18 (1998), págs. 157-167.

— «El austriacismo persistente y purificado 1734-1741», en Miguel Herrero y Ernest Lluch (eds.), Foralismo, derechos históricos y democracia, Bilbao, Fundación BBVA, 1998, págs. 49-84 [Versión anterior en La Catalunya vençuda (1996), págs. 55-92 y versión posterior en Las Españas vencidas (1999), págs 62-92].

- «La teoria política de l'austriacisme: el comte del S. R. I. Juan Amor de Soria», en Actes del IV Congrés d'Història Moderna de Catalunya i Europa a l'Edat Moderna [diciembre de 1998], Pedralbes, 18 (1998), págs. 601-620.

— «El pensament econòmic astur-castellà. Uns contrapunts», Afers, 30 (1998), págs. 349-358.

- «Jovellanos, prohibicionista», Cuadernos Aragoneses de Economía, 1 (1998), págs. 53-58 [Otra versión en Las Españas vencidas (1999), págs. 211-215].

- «La principessa filosofa, ossia «El desdén, con desdén», Recuperació de l'única òpera de Carles Baguer», Catalunya Música, XV, 161 (1998), págs. 6-7.

- Las Españas vencidas del Siglo XVIII: claroscuros de la Ilustración, Barcelona, Crítica, 1999.

— «Una dotzena de qüestions jansenistes», en Anales De la Real Sociedad Económica de Amigos del País 1997-1998, Valencia, RSEAP, 1999, págs. 293301 [Nueva versión en J. M. Puigverd (ed.) Bisbes, Il-lustració i jansenisme a la Catalunya del segle XVIII, Vic, Eumo Editorial, 2000, págs. 169-180].

— «El judici imperial sobre la «Via fóra als adormits»», Butlletí de la Societat Catalana d'Estudis Històrics, X (1999), págs. 67-88.

- L'alternativa catalana (1700-1714-1740). Ramon de Vilana Perlas i Juan Amor de Soria: teoria i acció austriacistes, Vic, Eumo Editorial, 2000 [2 edición: Vic, Eumo Editorial, 2001].

- «El industrialismo en la Corona de Aragón y en la Corona de Castilla (Siglo XVIII)», en Enrique Fuentes Quintana (dir.), Economía y Economistas Espa- 
ñoles. Vol. III: La Ilustración, Barcelona, Galaxia Gutenberg-Círculo de Lectores, 2000, págs. 567-582.

- «El cameralismo en España», en Enrique Fuentes Quintana (dir.), Economía y Economistas Españoles. Vol. III: La Ilustración, Barcelona, Galaxia Gutenberg-Círculo de Lectores, 2000, págs. 721-728.

-, (con Lluís Argemí) «La fisiocracia en España», en Enrique Fuentes QuinTANA (dir.), Economía y Economistas Españoles. Vol. III: La Ilustración, Barcelona, Galaxia Gutenberg-Círculo de Lectores, 2000, págs. 709-720.

— «Militarisme i castellanització a la València de després de 1707», [Recensión de Enrique Giménez, Gobernar con una sola Ley. Sobre la nova política borbónica a València, Alicante, Universidad de Alicante, 1999] L'Espill, 5 (2000), págs. 181-185.

- «Juan Amor de Soria y Ramon de Vilana Perles. Teoría y acción austracista», estudio introductorio en edición del Conde Juan Amor de Soria, Aragonesismo austracista (1734-1742), Zaragoza, Institución «Fernando el Católico« (CSIC)-Diputación Provincial de Zaragoza, 2001, págs. 9-183.

- «El programa polític de la Catalunya austriacista», en Joaquim AlbaredA (ed.), Del patriotrisme al catalanisme. Societat i política (segles XVI-XIX), Vic, Eumo Editorial, 2001, págs. 129-167.

— «L'austracisme a Figueres: Francesc Romà i Rossell» [Conferencia pronunciada en el Ayuntamiento de Figueres el 10 de setiembre de 1998], en Rafael PAScuet (ed.), Entrelluchs. Una aproximació empordanesa a Ernest Lluch, Figueres, Brau edicions, 2001, págs. 205-221.

— «Mayans, valencianista foral» [Entregado en octubre-noviembre de 2000 para su publicación en el Catálogo del Museo Valenciano de la Ilustración y la Modernidad, que se iba a editar con motivo de la inauguración del así llamado Museo. Las principales autoridades valencianas inauguraron dicho Museo en julio de 2001, pero misteriosa e inexplicadamente el previsto Catálogo no ha sido editado].

\section{Algunos comentarios}

El conjunto formado por el Catálogo de las estudios sobre el siglo XVIII y el gráfico sintético que los agrupa numéricamente por quinquenios nos proporciona una visión de conjunto y ordenada de la producción escrita dieciochista de Ernest Lluch. Probablemente para obtener una interpretación del pensamiento de Lluch sobre el siglo XVIII haya que partir de ahí. Y quizá sea necesario partir del siglo XVIII para obtener una interpretación del conjunto de su pensamiento. Con ellos tratamos de contribuir en las bases, que deberán tener también otras proceden- 
Número de estudios sobre el siglo XVIII en el periodo 1961-2000 (por quinquenios)

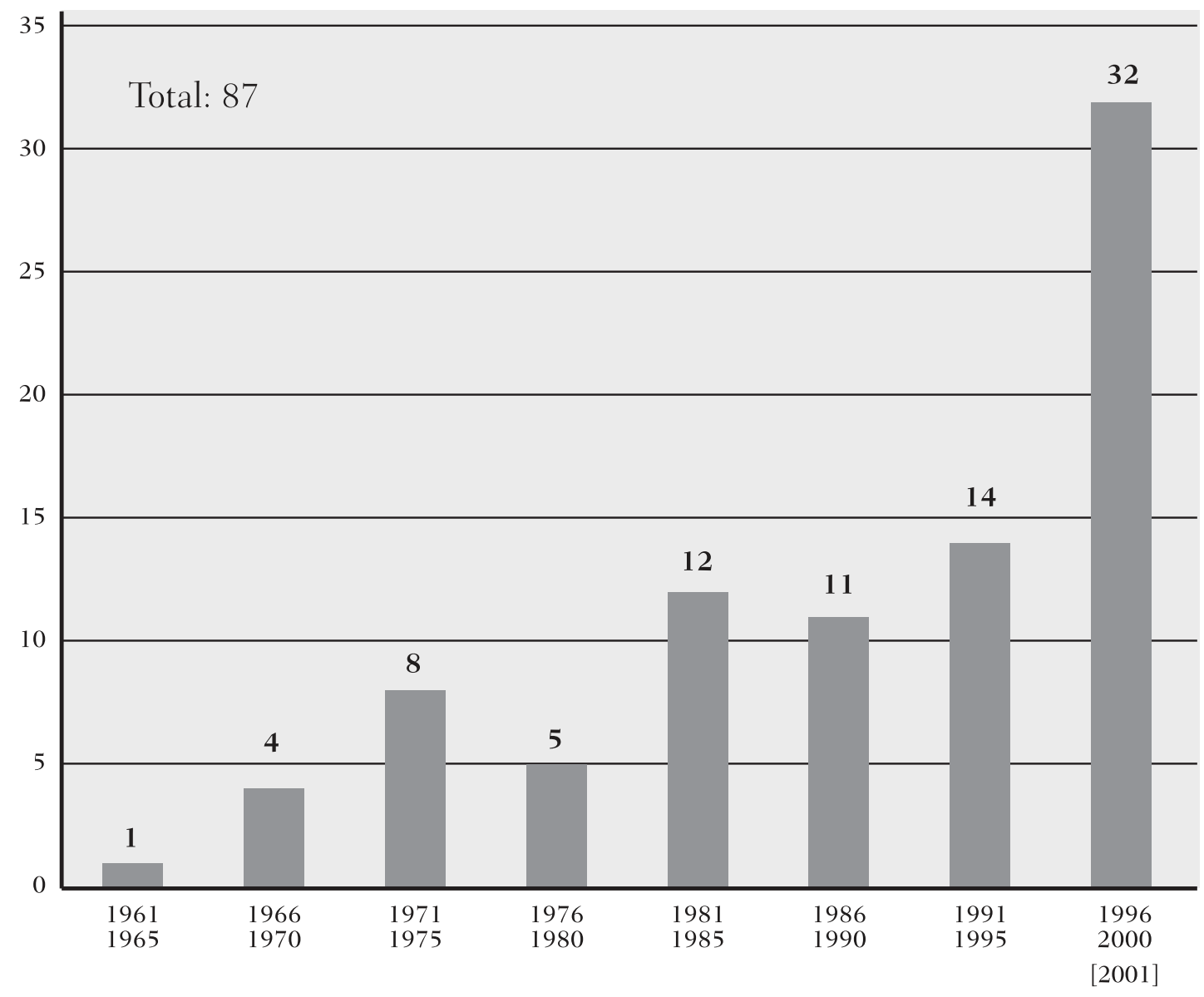

cias, para avanzar en dicha operación de ordenación, interpretación y evaluación de la obra de Lluch.

Una lectura atenta del Catálogo nos conduce, en primer lugar, al juego de títulos similares pero distintos que utilizaba Lluch, quizá influido consciente o inconscientemente por Jorge Luis Borges, y que hace difícil diferenciar lo que son trabajos distintos de lo que son meras versiones retocadas de un mismo trabajo. También llama la atención, en segundo lugar, la cuantía de trabajos: 87 según el catálogo, una cifra difícil de alcanzar por otros historiadores teniendo en cuenta que el número de escritos de Lluch (que es lo que se suele contabilizar) es muy superior, pues habría que sumar el de las las distintas versiones. Estamos pues ante uno de los mayores especialistas españoles en el XVIII aunque sólo sea por 
el criterio — nada baladí — del número de trabajos publicados. Otros criterios apoyarían esta calificación. Por último, del catálogo también podemos obtener las líneas de investigación en las que Lluch estaba progresivamente trabajando y su evolución. Como una primera aproximación a la cuestión podemos indicar las siguientes: autores (normalmente escritores económicos o economistas, aunque también políticos, sobre todo en los últimos años) catalanes, valencianos, vascos, aragoneses y astur-castellanos; reflexiones sobre la Ilustración y las instituciones ilustradas en Cataluña, Valencia, Aragón, etc.; difusión de la fisiocracia y el cameralismo en España y en Europa; investigaciones sobre el entorno religioso de las ideas económicas y en particular sobre el jansenismo dieciochesco; el pensamiento austracista tras la Guerra de Sucesión, el foralismo y en general una concepción pluralista de las Españas; estudios sobre los libros, la cultura, la música, los viajes... del siglo XVIII. Todo ello adobado con su interés por reconstruir el «cuasi-sistema» representativo del pensamiento económico en muchos países europeos, y que impedía identificar la ilustración con el liberalismo económico — pues el papel del Estado como impulsor del mercado y del progreso era fundamental, incluso en fechas tardías como los finales del mil setecientos o los principios del mil ochocientos-y utilizar una metodología propia del enfoque nacional de la historia del pensamiento con especial atención a los procesos internacionales de circulación y recepción de las ideas económicas. Dejaremos un análisis adicional de las complejas variaciones temporales de su interés por las diferenets líneas de investigación, además de las posibles convergencias y divergencias entre ellas, para otra ocasión.

El primer elemento que sobresale del cuadro sintético es el montante absoluto y relativo de la última columna sobre los trabajos editados durante el quinquenio 1995-2000 (y en la que por razones obvias se han incluido también los publicados en 2001). Refleja con toda claridad que a Ernest Lluch lo asesinaron en el momento de máxima productividad intelectual, al menos respecto al siglo XVIII (aunque este hecho se vería corroborado si utilizásemos toda la bibliografía de Ernest). En segundo lugar, el cuadro muestra también la existencia de dos etapas, delimitadas por el año 1980. Antes de 1980 hay un ligero y no sostenido crecimiento en las publicaciones cuyo número se ve algo dismunuido por la elección de Lluch como diputado por Girona, teniendo que compatibilizar durate unos años sus trabajos en la circunscripción gerundense, con su alojamiento y abundantes intervenciones parlamentarias en Madrid, sus clases en Valencia, sus vínculos con Barcelona y Vilassar, etc. Entonces fue cuando Lluch escribió un artículo de periódico afirmando que en realidad «vivía en la maleta». A partir de 1981 el número de publicaciones se duplica hasta 1996-2000 en que se produce una eclosión con 32 escritos publicados. En los cinco últimos 
años de su vida Lluch publicó sobre el siglo XVIII el 37 por ciento del total de sus trabajos al tiempo que su intrerés se ampliaba cada vez más desde la historia de pensamiento económico en términos estrictos a una visión más amplia en un sentido cultural y político; y hacia los inicios del XVIII español y las consecuencias políticas de la Guerra de Sucesión. La cuestión de qué límites o vericuetos hubiera realmente alcanzado Ernest Lluch con sus investigaciones de haberle dejado vivir es imposible de contestar, pero quizá nos pudiera dar alguna pista la dinámica del propio gráfico sintético y el título de sus trabajos.

\section{Sobre Mayans y sobre el socialismo: dos escritos de Ernest Lluch}

\section{Introducción}

A continuación reproducimos dos breves escritos de Ernest Lluch que son representativos de ese carácter ilustrado ambivalente del que hemos hablado, de especialista en la Ilustración y de defensor actual de los valores ilustrados.

El escrito «Mayans, valencianista foral» constituye el último trabajo sobre el siglo XVIII que llegó a escribir y fue enviado en octubre-noviembre de 2000 para su publicación en un Catálogo sobre Gregorio Mayans que se iba a editar con motivo de la inauguración del llamado Museo Valenciano de la Ilustración y la Modernidad. El escrito permanece inédito, pues aunque dicho Museo fue inaugurado por las primeras autoridades valencianas en julio de 2001 el Catálogo no fue editado, sin más explicaciones. No ha sido fácil conseguir una copia de este escrito, pues ni los responsables del Museo ni otros prestigiosos historiadores han querido proporcionarme copia de un trabajo que había discutido reiteradamnete con Lluch (por eso sabía de su existencia y remisión). El que reproduzco debe ser la segunda versión remozada y cambiada de título de un trabajo que originalmente se denominaba «Mayans, austracista» y que dadas las dificultades interpuestas aún no he conseguido localizar para reproducir y analizar las diferencias. En todo caso, el escrito es muestra de las preocupaciones del último Ernest Lluch por introducir nuevas perspectivas en el análisis del siglo XVIII, por el relieve concedido a cuestiones como el austracismo (en el caso de Gregorio Mayans, más bien sería el valencianismo foral) y la recuperación de una concepción de la España plural que iría desde los vencidos del siglo XVIII hasta la Constitución española de 1978 en donde se volvería a reconocer la pluralidad de las Españas.

El artículo sobre el socialismo es de naturaleza bien distinta. Desde la Fundación Ramón Campalans del Partido de los Socialistas de Cataluña le solici- 
taron que resumiera con máxima brevedad su concepción sobre el socialismo. En este notable texto de principios de 1999 Lluch se remite para fundamentar la sociedad socialista a los valores ilustrados de libertad, igualdad y fraternidad, a los cambios morales y éticos necesarios que deben de producirse en las personas; unos cambios que como el caso de muchos ilustrados españoles debían incorporar valores del catolicismo primitico y del cristianismo humanista, además de su insistencia en la educación, la formación y en los valores de la camadería en el trabajo, de la autogestión, de la obra bien hecha y otros conceptos más actuales pero que pueden derivarse de su raíz ilustrada o de su formulación en el siglo XVIII. La libertad seguía apareciendo como un fin en sí misma. Esa concepción en apariencia etérea del socialismo ligaba con su concepción de sociedad en ilustración, a la que nos hemos referido en el principio de esta nota, avanzando gracias a las luces hacia mayores cuotas de de libertad, de igualdad, de felicidad, de fraternidad... En Ernest Lluch tanto se puede hablar de un socialismo ilustrado como que el verdadero objetivo de la ilustración es avanzar hacia mayores cuotas de socialismo, entendido de acuerdo con su concepción. Socialismo ilustrado e ilustración socialista eran como dos caras de la misma moneda, dos procesos convergentes hacia el mismo fin. Y aquí radica una de sus aportaciones más notables y curiosas que merecerían un amplio debate histórico y actual.

\section{Mayans, valencianista foral}

Pense que una de les vertebracions del pensament de Gregori Mayans és ser conseqüent amb l'austriacisme de la seua família i que fou majoritari al Regne de València fins a la batalla d'Almansa i el Decret de Nova Planta de 1707. Un Decret que suposà l'abolició dels Furs i de les Corts valencianes així com la prohibició, secreta o pública, de la llengua pròpia dels valencians. El mateix succeí a Aragó el mateix 1707, a Catalunya el 1714 i a Mallorca el 1715. Tots reberen per igual però on hi havia un dret privat propi com a Aragó i Catalunya fou salvat mentre que al Regne de València que també el tenia fou prohibit malgrat posteriors promeses, sempre incomplertes, que seria permesa la seua recopilació i posada de nou en funcionament. Una mostra, per un costat, que la repressió dels vencedors fou molt més dura en el territori valencià de la Corona d'Aragó com, per un altre, que, posteriorment, no s'ha tingut el nervi per a recuperar-lo i crear-ne de nou quan ja és possible.

Gregori Mayans i Siscar nascut el 1699 viu eixe esfondrament d'una manera directa donat que el seu pare, en motiu de la desfeta del 1707 i per la seua posició política, marxà a Barcelona tot seguint al rei Carles III que havia estat Arxiduc pretendent i que esdevindria l'Emperador Carles VI. Vençuts els partidaris d'una Espanya 
«composta», a Barcelona l'onze de setembre de 1714, la família Mayans retorna a València on viuran la vida de l'exili interior tot i que mantindran alguna relació difícil o clandestina, sense rastres, amb Viena i una prova ben clara en donarem. Gregori quedarà inscrit en eixa «circumstància» tant per voluntat pròpia com per voluntat reial donat que Felip IV d'Aragó i Catalunya ara ja és solament Felip V d'Espanya quan, abans de 1707 i de 1714, compatibilitzava el seu títol aragonès amb el de Felip V de Castella. La duresa de qui ja era Felip V «por derecho de conquista» fou tan decidida que alarmà al seu avi Lluís XIV, que era conegut pel seu absolutisme unitarista, el qual li escriví que mantenguera les Constitucions dels catalans. La resposta a l'avi fou contundent basant-se en la raó que, si així ho feia, hauria de retornar també els furs a aragonesos i a valencians.

Cal tenir en compte que el foralisme tenia una gran contingut jurídic en part per la manca de convocatòria, per diversos reis, de les Corts valencianes. Açò obligava a que els notaris i els juristes anaren creant dret a partir dels acords anteriors de Corts tot adaptant-los a una realitat canviant. Aquesta tradició de gran rigor jurídic és la que visqué Mayans a Barcelona i, sobretot, a València i a la que la sòlida Universitat de Salamanca li donà formació. Pensem que el que definia la condició de valencià era un sistema jurídic propi més que la llengua o una història comuna. Eixa legislació impregnava la vida dels valencians tal com ho veurem en un episodi de la vida de Mayans. Cal defugir del terme austriacisme perquè el que era substantiu era la defensa dels furs i de les Corts valencianes. Una defensa que era més esperable d'un rei habsbúrgic que en un borbònic, nét de qui més s'havia distingit per un absolutisme unitarista sense precedents. Per tant, el substantiu era el foralisme valencià i l'adjectiu l'austriacista, tot i que en el transcurs de la guerra i del record eixe adjectiu anirà prenent força.

Alguns intèrprets de Mayans han pensat que podrien posar en qüestió el seu pensament de progrés en haver optat pel tradicionalisme dels Àustries i no per la modernitat dels Borbons. Parlem-ne. Les Corts valencianes no eren democràtiques com les actuals però anaren evolucionant cap una participació i, sobretot, ho foren molt més que l'alternativa d'un despotisme més absolutista que il.lustrat. Per açò, hi hagué resistència per part dels reis en convocar unes Corts que limitaven el seu poder. Així els països amb Corts tingueren uns dèficits pressupostaris menors que els absolutistes. La llibertat o, millor dit, uns espais de llibertat eren millor també econòmicament que un poder despòtic. Pels valencians anteriors a 1707, la possibilitat de futur hagués pogut ser més pareguda a l'evolució d'Anglaterra o dels Països Baixos per mitjà d'un reformisme successiu però en perdre la guerra de successió fou molt més pareguda a la de França, Prússia i Rússia. És difícil de sustentar, per no dir que impossible, que l'opció de recolzar o de recolzar-se en un rei austríac o de les Espanyes era menys modern que fer-ho en un rei unitarista. 
Dit tot açò, hem de convenir amb el màxim estudiós de Mayans, Mossèn Mestre que no totes les dificultats que tingué Mayans amb les autoritats borbòniques o amb la Cort tingueren el seu origen en l'austriacisme familiar. La seua independència de caràcter i la seua actitud crítica són factors a tenir en compte també en la seua marginació. De totes maneres, hi ha algunes característiques ideològiques de Mayans, fora del terreny polític, que són coincidents amb el que imperava dintre dels corrents que recolzaren l'austriacisme. Així ho era el seu catolicisme decidit, però encara més corrent que en el que dintre de l'església quedava inscrit. Així Mayans fou antijesuïta però sabem també que la companyia de Jesús, en termes generals, havia optat per la solució borbònica en els diversos territoris de la Corona d'Aragó. Era una antijesuïtisme decantat per l'agustinisme que fou la base del jansenisme donat que el títol del llibre del Bisbe fundador d'eixa corrent era «Agustinus». La proclivitat de Mayans cap eixes tendències és ben coneguda i mostra d'açò és que en la descripció de la seua mort consta que les hores immediatament anteriors havia «oido un rato la leyenda del incomparable Duguet, autor suyo privado y valido». Recordem que Jacques Joseph Duguet era oratià i un jansenista moderat que es va negar a signar el formulari antijansenista recolzar per Roma.

Des del punt de vista econòmic i social el jansenisme en el catolicisme jugà un paper relativament paregut al del calvinisme dintre del món protestant. La teoria que el vici privat pot ser una virtut pública (recordem que el millor forner no és el més bona persona sinó el que per voler acumular diners fa el pa més bo i més barat) fou el punt més bàsic d'Adam Smith, o la teoria dels contrapoders per Montesquieu segons la qual tot ha de ser controlat perquè tot està viciat (tot i que Mayans no el va acabar de comprendre) o bé el centrament en el treball sistemàtic com una virtut fonamental són tres aspectes típics del jansenisme i del liberalisme. El regalisme de Mayans també era un altre aspecte que l'aproximava al jansenisme tot i que no hi milités plenament. No hem d'oblidar que la muller de l'Arxiduc i futur Emperador Carles VI es tinguda per una jansenista de tot cor. Però els camins del Senyor són sempre inescrutables. De fet el seu nomenament com a bibliotecari reial de Mayans fou degut al recolzament d'un jesuïta excepcionalment austriacista que arribà al cardenalat. Aquesta pressió pogué tenir lloc el 1732 degut a que Felip V i el ja emperador Carles VI havien signat set anys abans el Tractat de Viena que tancava la Guerra de Successió.

Mayans, en el terreny més estrictament polític, jugà la carta del possibilisme dels austriacistes dins del sistema borbònic i així tingué excel-lents relacions amb el «partido aragonés» que encapçalava el Comte de Aranda. L'opinió sobre eixe polític, quan és cessat de la presidència del consell de Castella, és ben clar: «lo cierto es que el Señor Conde hará falta en Madrid, a todo el reino y aún, si puede decirse, al Rey; sus prendas, juicio, moderación, suavidad y acierto en su gobierno, con una 
Facsímil del manuscrito original sobre el socialismo

El vocialisme és portar la màxima llibestat, la maxima igualtat i la maxiuna fraternitats possibles a les pertones que viven en vocietat. Per abolin-ho norithi ha prove aub politiques pribliques, sino' que taube' cal que la suoral il'ebica de les persones canvii paral. Ielameut. Heur de canviar les cosey perio heu de canviar les persones. Penso que heen de fer noothes els valos del cristianisuce primitin $i$ del cristianitue humasista. Hem A'incosporar els valor de la companyonia dels treballadors a la feina $i$ a la sera organització autionoma. L'ètica del treball idela feina ben feta ens ha de vertebrat. Collectivanent hem de maldar per a que els flogells $i$ causes de desigualtat desepareguin 8 la por a la ma. lattia sense assittincia, la velecta oense secursos, el mo poder ethediar si es teren condicions i ganes. Volem taubé que la forruació de les persones ens permetin de frür del lleure d'una neavar creativa i enriquidora. Heue de fer aixo estenent la nostra mirade prop de noralties pero mirant a tot el planeta que volem conservar $i$ on la inmenta majionia visquice en condicions i en uma llikestat que és un fi en s'mateixa.

\section{Erustlluch i Martin}

dos de gever de 1999 
intención maravillosamente buena, ayudado de su perpicacia, le harán que se eche de menos. Yo no trato a su Exa., sino que he observado su conducta; y así no le soy adulador». El seu epistolari amb Roda i amb Aranda és prou significatiu. Hi ha constància de que Mayans rebé amb satisfacció les mesures de Carles III de Borbó (no confondre amb Carles III que fou el títol que adoptà l'Arxiduc) per treure despotisme del govern municipal en l'eliminar els regidors perpetus pel que acceptà dos nomenaments successius en eixe àmbit. Mayans al mateix temps celebrà el caràcter antisenyorial de la reforma el que cal connectar amb una característica fonamental dels valencians foralistes entre 1705 i 1707: la visió municipalista dels furs valencians, eliminada per Felip V, dóna un altre exemple del que volem dir és quan no prèn en compte les millores de la universitat sinó hi ha un retorn del paper de la ciutat de València: «pero pregunto: ¿sin restituirse el patronato a la ciudad, esto qué es?».

Naturalment que Mayans era un partidari de l'existència d'Espanya però d'una Espanya plural i d'eixa manera quan escriu a una autoritat del Consell de Castella amb motiu del Decret de Llibertat de comerç de grans li diu que ha de començar «por rogar a Dios que de a V.S. espíritu de docilidad para que aprenda de un valenciano las verdades que no sabe decir, ni conocen los castellanos, porque quieren que todo el mundo se gobierne por sus ideas, por las cuales se han perdido a sí mismos y quieren perder a los demás». La duresa de Mayans contra el que representaven els castellans té una virulència que mai cap valencià posterior ha igualat. Reproduïm un fragment destacat per Mossèn Mestre: «los castellanos quieren quitarnos aún la memoria de nuestra antigua libertad: gente enemiga de todo el género humano».

Respecte a la llengua distintiva dels valencians per entendre la seua posició cal tenir en compte les extraordinàries condicions adverses en que es mogué i, per tant, no fou molt àmplia. Però cal subratllar que els escassos defensors de la llengua dels valencians, el frare Lluís Galiana, Agustí Sales i més lluny el més destacat de tots Carles Ros, estigueren dins de l'òrbita de Gregori Mayans. Un grup reduït però important, que no tingué continuïtat degut en part a les oposicions oficials. Pensem, per exemple, en l'enemiga de la Real Academia de la Historia respecte a l'Acadèmia Valenciana que, per eixa causa, no pogué sobreviure. També és cert que el menyspreu per l'Acadèmia madrilenya per part de Mayans és brutal: «Hoy la Academia es una junta de ignorantes, y, por tal, está tenida en la Corte y fuera de España». La seua identificació amb el seu germà Joan Antoni ens porta a pensar que coincidien en pensar que el valencià, mallorquí, català i occità formaven una llengua comú que anomenaven llemosí. Una llengua que estava sotmesa a opressions externes i a un menysteniment intern com ho revela el següent fragment del germà de Mayans escrit el 1783: «Su lengua (de Catalunya) en España y en Francia hubo tiempo en que fue la más culta, pero en ambas partes ha tenido igual desgracia pasando de dueña a criada, y los interesados en su conversación son los primeros que 
la han abandonado con mayor o menor prisa. En esto los valencianos hemos ganado la palma como inmediatos al riñón de Castilla».

Ernest LLUCH

Professor de la Fundació Cañada Blanch de València

El artículo lo escribió el profesor Lluch mientras impartía un curso en la Cátedra de Pensamiento Contemporáneo de la Fundación Cañada Blanch y la Universidad de Valencia.

\section{El socialismo desde las Luces}

Traducción castellana [de V. LL.] del texto manuscrito de Ernest Lluch sobre el socialismo, fechado el 2 de febrero de 1999, perteneciente al Archivo Histórico de Socialismo Catalán de la Fundación Rafael Campalans.

El socialismo es proporcionar la máxima libertad, la máxima igualdad y la máxima fraternidad posibles a las personas que viven en sociedad. Para conseguirlo no son suficientes las políticas públicas, sino que es también preciso que cambie paralelamente la moral y le ética de las personas. Hemos de cambiar las cosas pero hemos de cambiar las personas. Pienso que hemos de hacer nuestros los valores del cristianismo primitivo y del cristianismo humanista. Hemos de incorporar los valores de la camaradería de los trabajadores en el lugar de trabajo y en su organización autónoma. La ética del trabajo y de la tarea bien hecha nos debe vertebrar. Nos hemos de esforzar colectivamente para que los flagelos y las causas de la desigualdad desaparezcan: el miedo a la enfermedad sin asistencia, a la vejez sin recursos, a no poder estudiar si se tienen condiciones y ganas. Queremos también que la formación de las personas permita gozar del tiempo libre de una forma creativa y enriquecedora. Debemos hacer todo eso extendiendo nuestra mirada cerca de nosotros pero mirando al mismo tiempo hacia todo el planeta que queremos conservar y donde la inmensa mayoría debiera vivir en buenas condiciones y en una libertad que es un fin en sí misma.

Ernest Lluch I MARTíN dos de enero de 1999 